THURSDAY, MARCH II, I 886

\section{THE SCIENTIFIC RELIEF FUND}

A TIME in which so many heartrending calls are being made upon the benevolent seems but ill-adapted for pressing any schemes not immediately connected with any specially urgent distress. There is, however, at present an appeal being made by the Royal Society to all who are in any way interested in science, which, though on behalf of a permanent fund, and not connected with any ephemeral distress, has long been felt to be necessary, and which peculiar circumstances render it imperative now to press forward without delay.

For some years past the Scientific Relief Fund administered by the Royal Society has been found insufficient properly to meet the numerous claims made upon it, and the Committee in charge of the Fund has been frequently hampered in its action in consequence. Of course the demands upon it are variable in their character and extent, being chiefly dependent on what may be called the chapter of accidents; but there are few years that pass without some one of greater or less scientific repute being carried off by an untimely death without having made due provision for those whom he leaves behind him; and perhaps fewer years still in which some earnest worker is not laia low by sickness, and finds himself reduced by an unforeseen chain of circumstances to a condition in which a grant from a fund administered by his scientific brethren is of inestimable value both materially and morally.

The income of the Scientific Relief Fund has not hitherto exceeded some $250 l$. per annum, its capital at the close of last year being about $7500 /$. With the view of increasing this capital sum to at least $20,000 \mathrm{l}$. a most munificent offer has been made by Sir William Armstrong, who was among the original founders of the Fund. It is that he will present $6500 l$. to the Fund provided certain conditions are fulfilled, the principal of which is that an equal amount be raised from other sources within the current year. We earnestly hope that there may be no difficulty in accomplishing this, and, with the view of making the scope and character of the Fund inore fully understood, we annex a few explanatory particulars.

It was in the year 1859 that the idea of creating a Scientific Relief Fund occurred to the minds of the late Mr. Gassiot and some other Fellows of the Royal Society, and the regulations under which it was to be administered were carefully considered, and, having been adopted by the Royal Society, have remained practically unchanged until the present day. The object of the Fund is defined to be for the aid of such scientific men or their families as may from time to time require and deserve assistance. Cases, however, can only be entertained on the recommendation of a President of one of the chartered Societies, it being understood that he consults the Councils over which he presides as to the person whom he intends to recommend for relief. The Committee administering the Fund, though Fellows of the Royal Society, are not members of its Council, and the senior member of its body retires annually, another Fellow being appointed in his place. It will thus be seen that VOL. XXXIII.-NO. 854 every reasonable precaution has been taken for the impartial and judicious administration of the Fund; and since its foundation nearly a hundred recipients of welltimed grants have had reason to bless its existence.

It may perhaps be said that men of science ought to be able to foresee what is coming, and be prepared to meet all the changes and chances of this mortal life, ar 1 possibly as a class they are more than usually exempt from those reverses of fortune to which all are liable. It is, however, the unforeseen that constantly occurs, and the temporary aid which, by means of such a Fund, a man can receive from a committee of his fellow-workers may be accepted with all gratitude, and without that humiliation which would be felt did the relief proceed from any more ordinary source of charity.

But although men of science may as a rule be prudent, it can hardly be said that they are as a class rich. Their researches may aid others in the acquisition of material wealth, but the cases are exceptional where the pursuit of science has brought large pecuniary gains to the student. Where it has, we are confident that others besides Sir William Armstrong will aid those less fortunate in this particular than themselves by contributing liberally to this Fund.

There is, however, another and important class of persons whose ample fortunes have been the result of the judicious application of science in economic pursuits, and we may be sure that the wants of the Fund have only to be brought under their notice to assure ready and efficient aid in raising the amount necessary to meet Sir William Armstrong's munificent offer. Already we see on the list a noble subscription of five hundred guineas from Mr. Ludwig Mond, and we venture to hope that by thus giving publicity to what is at present being done to enlarge the scope of this most useful Fund, others directly and indirectly interested in science may be led to follow so generous an example.

Looking at the extent to which the material welfare of this country has now for many years been intimately connected with its scientific progress, the debt due from all to the workers in science must at once be appreciated, and a more practical manner of acknowledging this indebtedness can hardly be suggested than that of contributing to the Scientific Relief Fund.

\section{THE BOTANY OF THE ROCKY MOUNTAIN REGION}

Manual of the Botany of the Rocky Mountain Region, from New Mexico to the British Boundary. By John M. Coulter, Ph.D., Professor of Botany in the Wabash College. (New York and Chicago : Ivison, Blakeman Taylor, and Co, I885.)

CHE object of this manual, as stated in the preface, is to do for the range of country in which the plants it describes are found, what has for a long time been so admirably done for the North-Eastern States of the Union by Asa Gray's manual. It hence affords a means of comparison between two distant areas, each of such considerable dimensions as to throw much light on the flora of temperate North America. And not only with the flora of the Eastern States does it compare, for, the botany of the great Western area included in California U 